\title{
Article \\ Determination of the Angle of Repose and Coefficient of Rolling Friction for Wood Pellets
}

\author{
Marcos A. Madrid ${ }^{1}$, José M. Fuentes ${ }^{2}\left(\mathbb{D}\right.$, Francisco Ayuga ${ }^{2}\left(\mathbb{D}\right.$ and Eutiquio Gallego ${ }^{2, *} *$ \\ 1 IFLYSIB—CONICET and UTN-FRLP, 1900 La Plata, Argentina; mmadrid@iflysib.unlp.edu.ar \\ 2 BIPREE Research Group, Universidad Politécnica de Madrid, 28040 Madrid, Spain; \\ jm.fuentes@upm.es (J.M.F.); francisco.ayuga@upm.es (F.A.) \\ * Correspondence: eutiquio.gallego@upm.es; Tel.: +34-910-670-938
}

check for

updates

Citation: Madrid, M.A.;

Fuentes, J.M.; Ayuga, F.; Gallego, E. Determination of the Angle of Repose and Coefficient of Rolling Friction for Wood Pellets. Agronomy 2022, 12, 424. https://doi.org/10.3390/ agronomy12020424

Academic Editors: Adriana Correa, María Dolores Gómez-López and Jesús Montero Martínez

Received: 20 January 2022

Accepted: 6 February 2022

Published: 8 February 2022

Publisher's Note: MDPI stays neutral with regard to jurisdictional claims in published maps and institutional affiliations.

Copyright: (C) 2022 by the authors. Licensee MDPI, Basel, Switzerland. This article is an open access article distributed under the terms and conditions of the Creative Commons Attribution (CC BY) license (https:// creativecommons.org/licenses/by/ $4.0 /)$.

\begin{abstract}
The determination of the angle of repose for granular materials is indispensable for their handling and the design of containers and technological processing equipment. On the other hand, computational simulations have become an essential tool to understand the micro-behavior of the granular material and to relate it with the macro-behavior. The experimental determination of the angle of repose has a fundamental role when defining the required parameters to perform realistic simulations. However, there is a lack of a standard that allows the reproducibility of the experiments when using granular materials of equivalent spherical radius greater than $2 \mathrm{~mm}$, such as corn, soybeans, wheat and PLA pellets, among others. In particular, a product of growing importance in the global strategy of decarbonization of the economy is biomass pellets, whose handling operations are one of the main components for the total cost of pellets supplied to the final user. In the present work, with the aim of determining the rolling friction coefficient, the variations in the angle of repose with the drop height for biomass pellets were studied both experimentally and with simulations, and an optimal procedure for its determination was found. Then, a calibration of the coefficient of rolling friction was performed through computational simulations using the discrete element method. The accuracy of the model under different configurations was checked.
\end{abstract}

Keywords: biomass; wood pellets; angle of repose; coefficient of rolling friction; DEM; simulation

\section{Introduction}

Granular materials (cereal grains, aggregates, flours, powders, pharmaceutical products, etc.) are the second most used materials in human activities worldwide [1]. Industry uses a large variety of granular materials covering an extremely broad range of shapes and sizes, and considering a lot of micromechanical and chemical properties. It is estimated that roughly one-half of the products and at least three-quarters of the raw materials employed by the chemical industry, on a weight basis, are in the form of granular solids [2]. As it turns out, any advance in understanding the physics of granular materials or the influence of environmental and handling conditions on their properties is bound to have a major economic impact.

On the other hand, the use of biomass for the production of energy has increased significantly in recent years as part of the global strategy for reducing our dependence on fossil fuels $[3,4]$. Solid biomass covers a multitude of materials generated by industrial processes or directly provided by forestry and agriculture, such as firewood, wood chips, sawdust, shavings, bagasse, animal waste or other solid plant residues, among others, which are mainly used to produce heat and electricity [5]. Wood pellets and briquettes are made by compressing dry sawdust or wood shreds under high pressure. The process of densification increases bulk density and facilitates logistics, transportation and handling operations [6]. The use of wood pellets as fuel is rapidly increasing all over the world [7]. In 2019, pellet production in the world represented more than 55.7 million tons [8]. 
Wood pellets can be considered to be a specific type of granular material, and their storage conditions can have a significant impact on their properties, mainly because they can be subjected to freezing and defrosting processes [9], or changes in their moisture content [10]. The change in the moisture content of wood pellets has been demonstrated to have a significant effect on their durability and mechanical properties, e.g., modulus of elasticity and flexural strength, pellet attrition or bulk density [10,11].

In addition, handling operations such as transport and storage are not free of durabilityrelated problems [12,13]. The durability and bulk density of the pellets are the main factors that affect their quality since they are critical for handling and storage operations [12] Pellets are susceptible to mechanical wear during these operations, which results in more fines, increasing the slide angle of the material and the amount of dust in handling operations [14]. They may also suffer changes in their properties $[11,15,16]$ and are at some risk of spontaneous combustion [17]. Optimizing the equipment and processes involved in their handling and management is therefore an important issue.

Pellets have long been stored in silos or large hoppers during the different stages of their processing. This storage is subject to problems of clogging, segregation of the stored material, propagation of rarefaction waves, particle packing, self-heating or dust concentration. All of these problems have been analyzed using numerical methods [18-21] In particular, the discrete elements technique has been widely used [22] since it allows analyzing the behavior of each stored particle, providing a detailed view of the phenomena that take place inside storage silos [23-26]. Such modeling requires many of the stored material's mechanical parameters to be known, including its density, elastic modulus and coefficient of restitution $[27,28]$.

When stored in silos, the behavior of granular materials differs from that of fluids in that a large part of the stored weight is transmitted to the walls through friction. It is essential, therefore, that the particle-wall coefficient of friction be known, as must the particle-particle coefficient of friction (both their linear and rolling components). Unlike that seen with irregularly shaped particles, the cylindrical shape of pellets, which share two planes of symmetry with spheres, means that the coefficient of rolling friction has a significant influence on the frictional phenomena that occur within the stored material [29]. There are several ways-largely based on the use of inclined planes-in which this variable can be determined experimentally [30]. However, these experiments can be difficult to perform and only provide realistic values for virtually spherical particles. Agarwal et al. [30] reported that the distortion of the results from reality increases significantly as particles become less spherical. Thus, the coefficient of rolling friction is usually obtained via an indirect calibration procedure after experimentally obtaining the material's angle of repose, plus a comparison with that obtained via simulations involving the discrete elements technique [31]. The mechanical variables of the stored particles are deemed constant in numerical simulations, except for the coefficient of rolling friction, which is modified until the angle of repose obtained in the simulation is the same as that obtained experimentally.

The angle of repose is a property of granular materials frequently used to validate discrete element models developed to simulate the behavior of such materials. Once the numerical model has been validated, it is possible to use it in order to analyze many handling problems associated with transport or storage conditions at an industrial scale, e.g., blockages, unexpected overpressures or low mass flow rates. The results obtained can lead to changes in the design of some elements, with a significant reduction in costs since it is not required to develop experimental facilities for all the alternatives considered.

Although the angle of repose can be measured experimentally in several ways [32,33], "piling" is the most commonly used method. This involves storing a representative mass of the material in a funnel and allowing it to fall freely from the funnel outlet at a given height [34]. Since the angle of repose obtained needs to be accurate, several procedures and algorithms have been developed to obtain its value from images of the pile of material that forms during the experiment $[35,36]$. Piling assays for granular materials is based on the procedures described in different international standards [37,38]. However, none of these 
specify all the factors that could influence the angle of repose based on the size and shape of particles tested, such as the aperture of the funnel outlet, the distance through which the material falls, or the way in which the material is received on the base plate. Moreover, the particles generally considered in these standards are powders or quasi-spherical particles, while pellets are cylindrical.

The present work analyzes the applicability of a pilling standardized assay for measuring the angle of repose for biomass pellets. This research has focused on analyzing the effect of the drop height, the base material receiving the pellets or the outlet size, which are aspects not properly defined in the current standard for wood pellets or any material or particle size. The aim of this study was to propose an optimized procedure that allows reproducibility and avoids sources of error. Numerical simulations were also performed to obtain the coefficient of rolling friction, and to examine the effect of the different coefficients of friction on the adopted angle of repose. The numerical simulations were validated with the experimental results, in order to obtain a discrete element model that could be used in further studies with regards to the handling of biomass pellets.

\section{Materials and Methods}

\subsection{Properties of the Examined Material}

The pine-wood pellets used in this work had an apparent mean density of $660 \mathrm{~kg} / \mathrm{m}^{3}$. Table 1 shows the dimensions and moisture content as experimentally obtained by the authors [39], and the values for other properties (calorific power or apparent density without and under compaction) as provided by the manufacturer (Coterram Generation S.A.). Durability Index was also provided by the manufacturer, and it was calculated following the EN ISO 17831-1:2015 standard [40].

Table 1. Pellet dimensions and physical properties.

\begin{tabular}{cc}
\hline Variable & Mean (Range) \\
\hline Length $(\mathrm{mm})$ & $17.70(8.33-27.98)$ \\
Diameter $(\mathrm{mm})$ & $6.08(5.96-6.21)$ \\
Volume $\left(\mathrm{mm}^{3}\right)$ & $513.89(244.24-799.05)$ \\
Moisture content $(\%)$ & $2.5(2-3)$ \\
Calorific power $(\mathrm{kcal} / \mathrm{kg})$ & $4803(4570-5029)$ \\
Apparent density without compaction $(\mathrm{kg} / \mathrm{l})$ & $0.660(0.628-0.688)$ \\
Apparent density under compaction $(\mathrm{kg} / \mathrm{l})$ & $0.706(0.674-0.732)$ \\
Durability Index $(\%)$ & $99.79(99.72-99.82)$ \\
\hline
\end{tabular}

\subsection{Procedures for Determining the Pellets' Angle of Repose}

The apparatus used to measure the angle of repose was constructed according to that proposed in Spanish standard UNE 55547:1981 [41], which follows the same procedure in ISO 4324:1977 [38] for determining the angle of repose for powdered and granular materials. Its value is obtained by allowing $150 \mathrm{~mL}$ of the test material to fall from the outlet of a glass funnel (outlet diameter $10 \mathrm{~mm}$ ) set at a height of $75 \mathrm{~mm}$, landing on a metallic base plate (diameter 100-150 mm) with a slightly rough surface, situated over a perfectly flat, horizontal plane. Once the funnel has emptied, the angle of repose is determined from the height of the cone of the collected material (the pile) and the diameter of the pile's base.

The apparatus used in the present work (Figure 1) was made using slotted aluminum rods. Its dimensions were adapted such that an adequate volume of pellets could be used to form a pile and to prevent blockages occurring in the funnel outlet tube. Each of the three 500-mm-high supporting columns, all equipped with a graduated scale, were fastened to a 2-mm-thick base plate (upon which a cylindrical collecting recipient could be placed if required). A funnel (inlet diameter $210 \mathrm{~mm}$, outlet diameter $60 \mathrm{~mm}$ ) was set between the three columns using a 15-mm-wide/2-mm-thick steel ring, which allowed the height of the funnel above the base plate to be varied. The required funnel outlet diameter $(60 \mathrm{~mm})$ was determined from the mean pellet spherical equivalent, and taking into account that, 
to avoid blockages, the funnel outlet needed to be at least six times the diameter of that theoretical sphere [2].
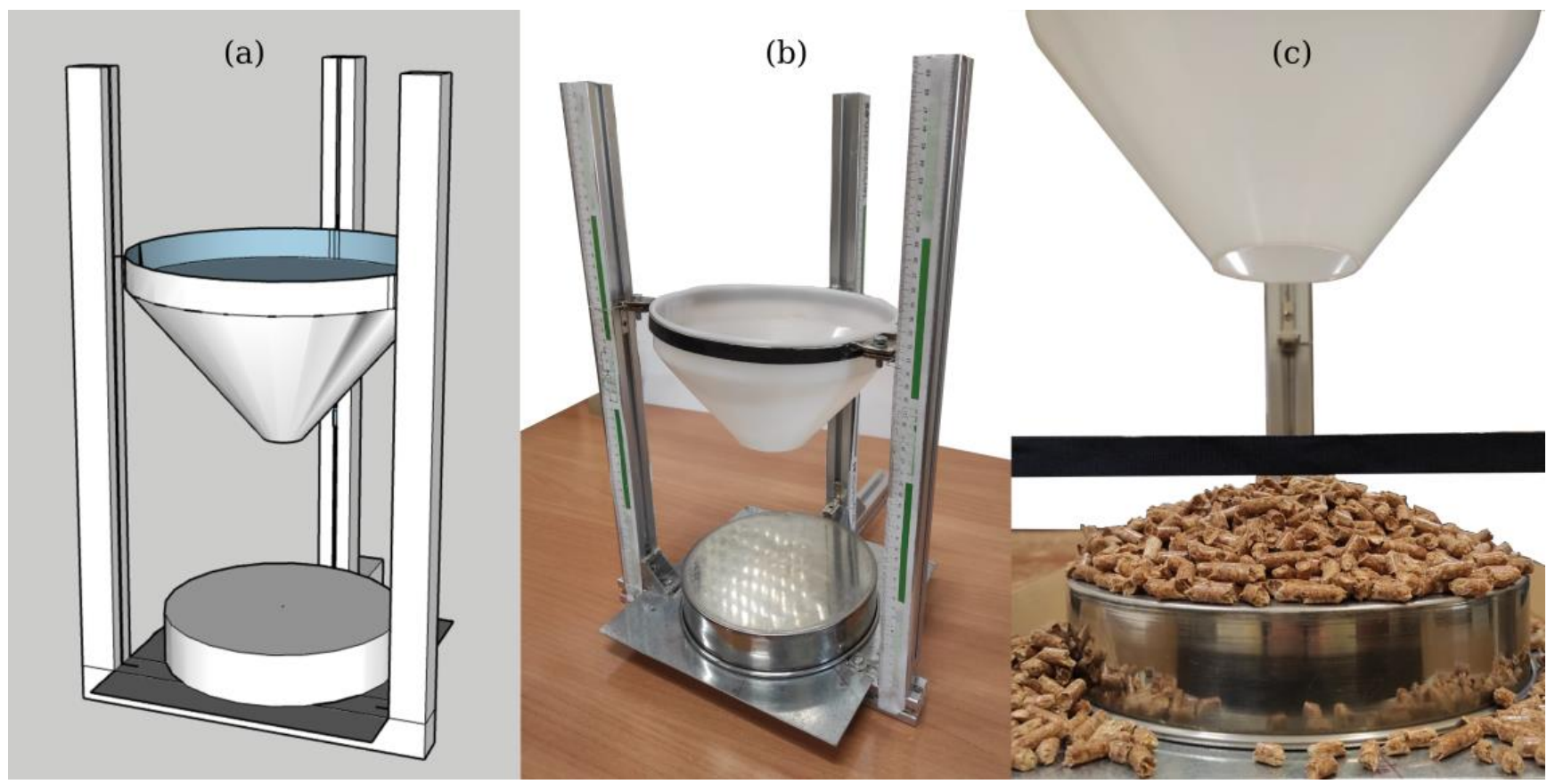

Figure 1. (a) Diagram of the experimental apparatus. (b) Photograph of the experimental apparatus. (c) Assay in progress.

When performing an assay, the funnel outlet is first blocked, and the funnel filled with pellets. The outlet is then unblocked and the material allowed to fall freely. After $30 \mathrm{~s}$, the height of the pile of pellets formed is measured (performed in triplicate from different points) (Figure 1c). The assay is then repeated.

In the present work, the drop height was set at 60, 75, 90, 105, 120, 135 and $150 \mathrm{~mm}$, and tests were repeated 6 times for each of the heights, obtaining a good repeatability (coefficient of variation less than $3 \%$ in all cases). The wood pellets were replaced after testing two different heights in order to avoid any wear-induced changes to the pellets' mechanical properties.

\subsection{Simulations Using the Discrete Elements Technique}

\subsubsection{Contact Model}

Numerical simulations were performed using the discrete elements technique developed by Cundal and Strack [22]. This allows the mechanical behavior of particles that interact with one another, and with the walls of their container, to be examined. Each particle is simulated individually as a rigid object. Their rotation and displacement are described via Newton's Second Law of Motion, taking into account the forces and moments that appear in the above interactions.

The contact force $F$ acting between the particles is composed of the normal force $F_{n}$ and the tangential force $F_{S}$, while the moment $M$ is composed of $M_{S}$ caused by the tangential force, and $M_{r}$ caused by the relative rotation of the particles. The model used to simulate the particle-particle and particle-wall contacts was Hertz-Mindlin, which assumes viscous damping to operate in both the normal and tangential direction, and that frictional damping occurs in the tangential direction [42]. The normal contact force at any instant in time, $F_{n}$, is given by the elastic component $F_{n}^{e}$ and the viscous damping moment $F_{n}^{d}$ as shown in Equations (1) and (2).

$$
F_{n}^{e}=\frac{4}{3} \cdot E^{*} \cdot \sqrt{R^{*}} \cdot \delta_{n}^{3 / 2}
$$




$$
F_{n}^{d}=C_{n} \cdot\left(8 \cdot m^{*} \cdot E^{*} \cdot \sqrt{R^{*} \cdot \delta_{n}}\right) \cdot v_{n, i j}
$$

where

$$
\begin{aligned}
E^{*} & =\frac{E}{2 \cdot\left(1-v^{2}\right)} \\
R^{*} & =\frac{R_{i} \cdot R_{j}}{R_{i}+R_{j}} \\
m^{*} & =\frac{m_{i} \cdot m_{j}}{m_{i}+m_{j}}
\end{aligned}
$$

where $\delta_{n}$ is the normal superimposition between particles; $m_{i, j}$ and $R_{i, j}$ are the mass and radius, respectively, of the particles $i$ and $j ; E, v$ and $C_{n}$ are Young's modulus, the Poisson coefficient and the normal damping coefficient, respectively; $v_{n, i j}$ is the normal velocity relative to a pair of particles $(i, j)$ in contact.

The tangential contact force between the particles in the present model reflects the theory of Mindlin and the law of Mohr-Coulomb. Thus, the tangential force $\boldsymbol{F}_{\boldsymbol{S}}$ includes the elastic force $F_{s}^{e}$ and the viscous force $F_{s}^{d}$ given by Equations (6) and (7)

$$
\begin{gathered}
F_{s}^{e}=\mu_{s} \cdot\left|F_{n}^{e}\right| \cdot\left(1-\frac{\left(1-\min \left(\delta_{t}, \delta_{t, \text { max }}\right)\right)^{3 / 2}}{\delta_{t, \text { max }}}\right) \cdot \bar{t} \\
F_{s}^{d}=C_{t} \cdot\left(6 \cdot \mu_{s} \cdot m^{*} \cdot\left|F_{n}^{e}\right| \cdot \frac{\sqrt{1-\min \left(\delta_{t}, \delta_{t, \text { max }}\right)}}{\delta_{t, \text { max }}}\right)^{1 / 2} \cdot v_{t, i j}
\end{gathered}
$$

where $\mu_{s}$ is the coefficient of sliding friction, $C_{t}$ the coefficient of tangential damping, $v_{t, i j}$ the relative tangential velocity of a pair of particles in a contact, $\bar{t}$ the unit vector along the tangential direction, $\delta_{t}$ the tangential displacement, and where

$$
\delta_{t, \max }=\frac{\mu_{s}(2-v)}{2(1-v)} \cdot \delta_{n}
$$

The moment $M_{r}$ caused by the rolling friction between the particles is derived via Equation (9)

$$
M_{r}=\mu_{r} \cdot R_{i} \cdot\left|F_{n}\right| \cdot \hat{\omega}_{i j}
$$

where $\mu_{r}$ is the coefficient of rolling friction and $\hat{\omega}_{i j}$ the relative velocity of rotation between particles.

\subsubsection{Parameters Used in the Simulations}

All calculations were made using EDEM Altair software [43], employing the HertzMindlin contact model to simulate the particle-particle and particle-wall contacts as well as the variables shown in Table 2 . The time step $(\Delta \mathrm{t})$ in all simulations was $1 \times 10^{-6} \mathrm{~s}$, corresponding to $1.5 \%$ of the critical time $\left(\Delta \mathrm{t}_{\mathrm{c}}\right)$, as determined using the Rayleigh criterion [44].

Table 2. Mechanical properties of the pellets; values used in simulations.

\begin{tabular}{ccc}
\hline Variable & Mean & Standard Deviation \\
\hline Particle density $\left(\mathrm{kg} \cdot \mathrm{m}^{-3}\right)$ & 1227 & 18.02 \\
Elastic modulus $(\mathrm{MPa})$ & 73.33 & 25.43 \\
Particle-particle coefficient of restitution & 0.62 & 0.058 \\
Particle-wall coefficient of restitution & 0.5 & 0.063 \\
Particle-particle coefficient of friction & 0.49 & 0.07 \\
Particle-wall coefficient of friction & 0.2 & 0.05 \\
\hline
\end{tabular}

The discrete elements simulations were performed contemplating 1000-2500 particles. The shape of the pellets was obtained from an approximation to their real cylindrical shape 
using the multispheres method [45]. This generated particles as groupings of 2, 3, 4, 5, 7 or 8 spheres each with a diameter of $6 \mathrm{~mm}$. The individual spheres used are partially overlapped in order to reach the desired lengths, and to approximately adjust their volumes to $250,350,450,550,650$ and $750 \mathrm{~mm}^{3}$, respectively (Figure 2).

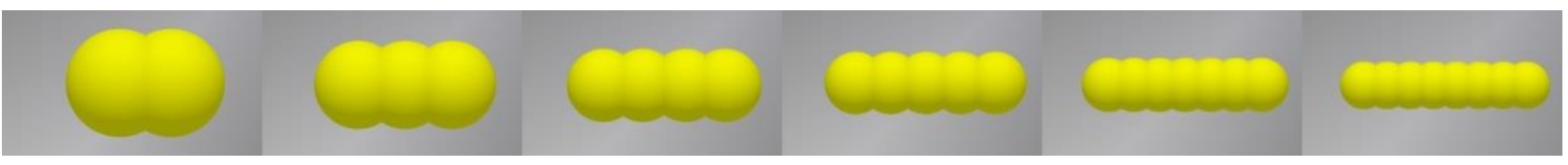

Figure 2. Generation of different length pellets using the multispheres method.

The percentage of each of the six types of particles used in the simulations was established from measurements on a sample of 100 randomly selected real pellets (Figure 3).

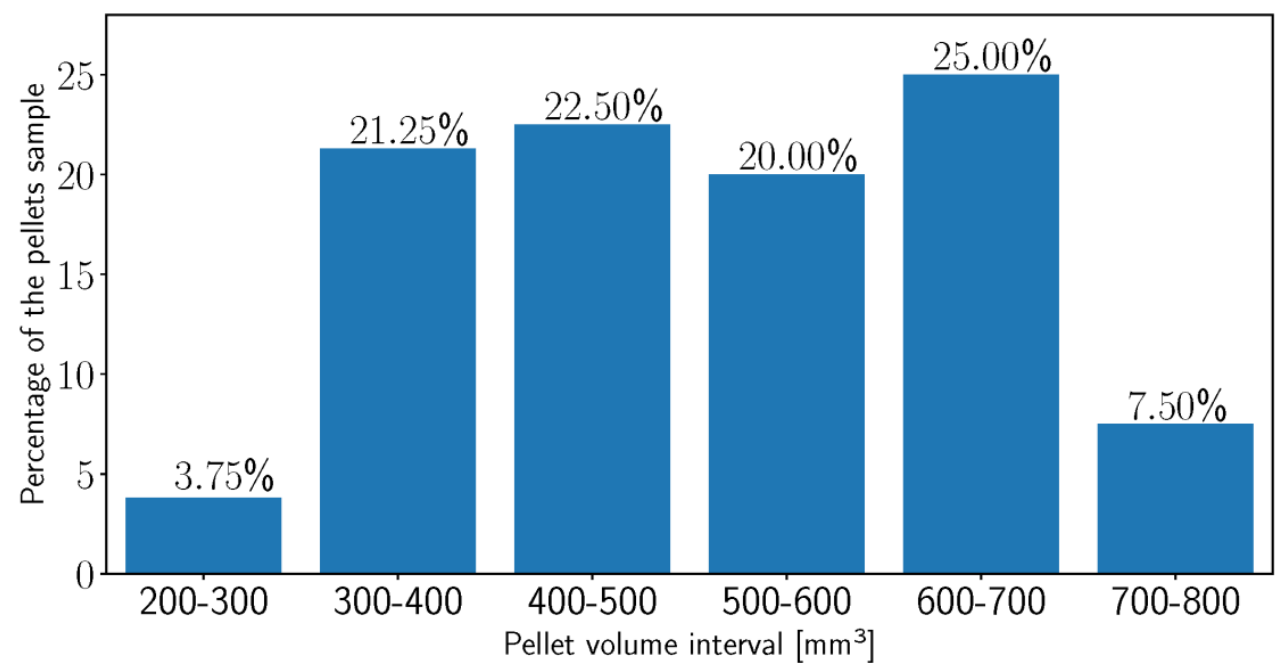

Figure 3. Size (volume) distribution of the pellets used in the experiments.

The means and standard deviation (SD) values for the different microscopic properties of the pellets required for the simulations were determined by direct measurement (Table 2).

The density of the particles was obtained using the pycnometric method [46], measuring the volume of water displaced by five samples of pellets of mass $35-40 \mathrm{~g}$. The elastic modulus of individual particles was obtained following the method provided in ASAE 368.4:2006 standard [47], using compression assays involving 25 particles and employing an XT2 Texture Analyzer (Stable Micro System Ltd., Godalming, UK) equipped with a $250 \mathrm{~N}$ load cell and a spherical compression tool (diameter $3.18 \mathrm{~mm}$ ).

The particle-particle and particle-wall coefficients of restitution were determined, respectively, following the procedures of $[28,48]$. The former contemplates the collision of particles in the form of a double pendulum, while the second sets the initial drop height and obtains the maximum rebound height of the particles from a flat sample of the silo wall material (stainless steel in the present work). Assays were performed with 3-5 samples of pellets, and using different drop heights (10-15 repetitions). Individual pellets were placed on a tipping platform (inclinable at a constant velocity), and the angle of inclination measured at the instant the pellet began to move. The particle-wall coefficient of friction was determined using a stainless steel tipping plate; the particle-particle coefficient was determined using a wooden tipping plate.

For the numerical simulations, a cylinder of radius $90 \mathrm{~mm}$ and height $20 \mathrm{~mm}$ was contemplated as a random particle generator. The generated particles were allowed to fall freely from a funnel with the same dimensions as used in the physical experiments. The funnel outlet was blockable via a limiting surface; when the particles were at rest in the funnel, the limiting surface was removed and the particles were allowed to pile on the plate 
below. The angle of repose was determined from the images produced when the pellets stopped falling. Simulations were repeated 5-10 times at different heights given the error inherent in the use of non-spherical particles, and to take into account the variation seen in the experimental assays. The numerical simulations performed aimed to reproduce the experimental tests carried out, as is shown in Figure 4.

(a)

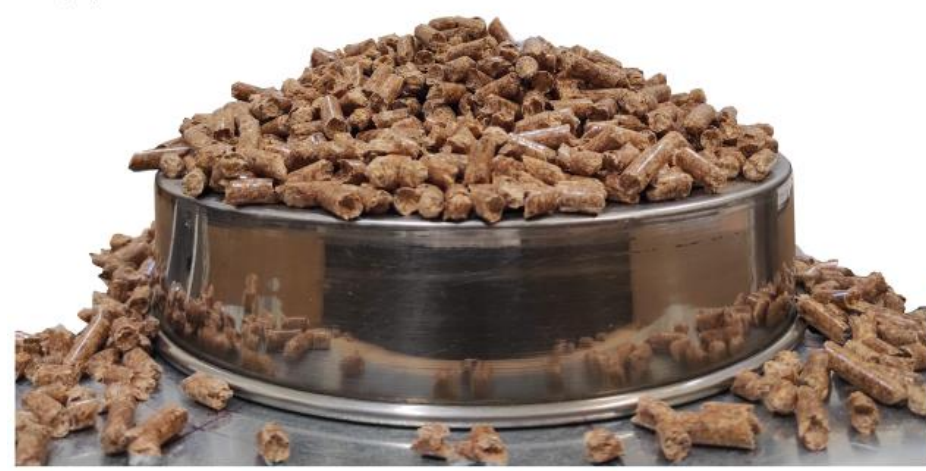

(b)

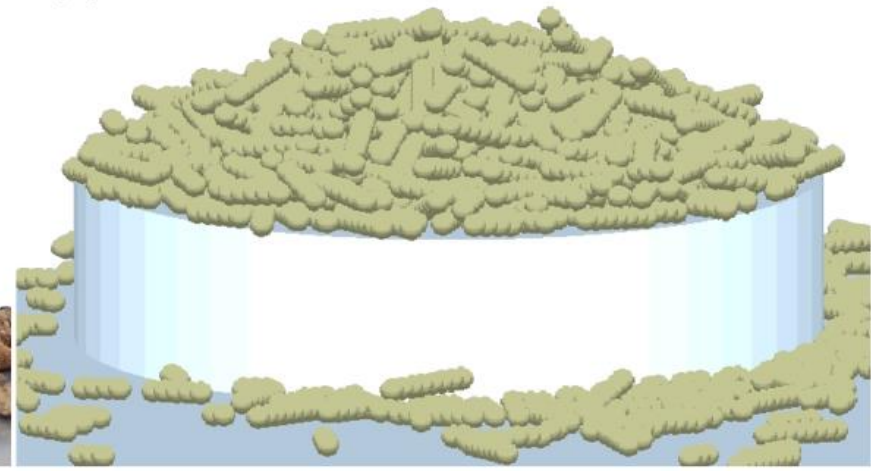

Figure 4. Comparison of results for a representative assay. (a) Experimental test; (b) numerical simulation.

\section{Results}

\subsection{Experimental Results}

Figure 5 shows the angles of repose obtained for the different drop heights when using a circular (102 mm radius) base plate (the piling surface) made of stainless steel. The points represent the mean values obtained for each height; the shaded area represents the standard deviations (SD). The angle of repose decreased significantly with drop height, showing it is important to specify the value of this variable.

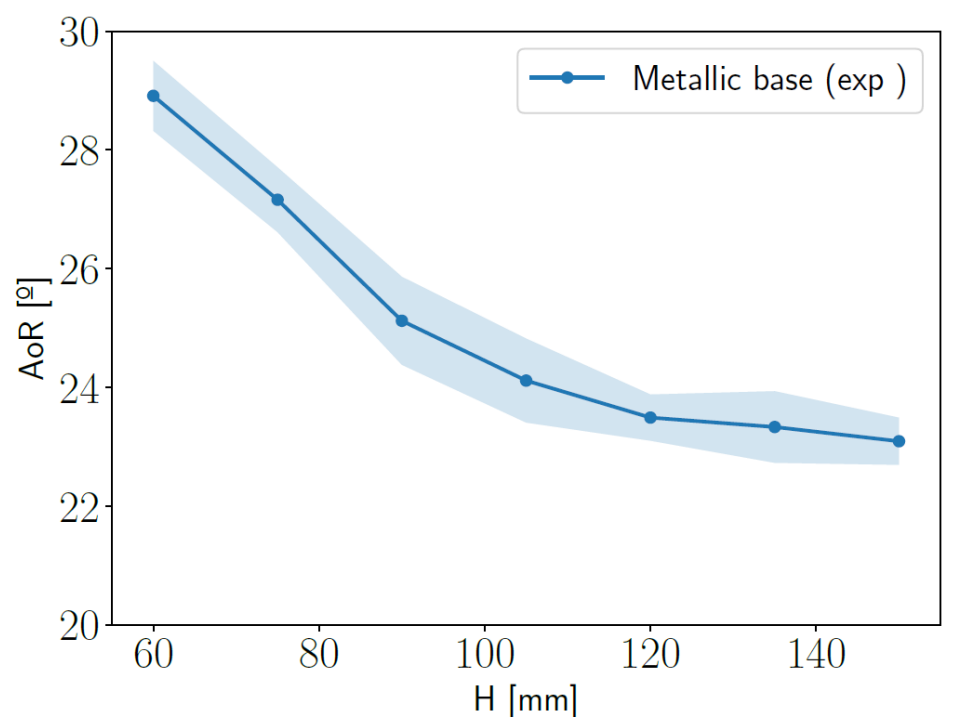

Figure 5. Variation in the angle of repose (AoR) with respect to drop height $(\mathrm{H})$.

The variation in the angle of repose was not linear. The slope for heights below $60-80 \mathrm{~mm}$ was around $0.13^{\circ} / \mathrm{mm}$, but decreased as the drop height increased until reaching about $23^{\circ}$ for heights of over $120 \mathrm{~mm}$. According to UNE 55547:1981 standard, the drop height should be $75 \mathrm{~mm}$ - the height at which, here, the change in the angle of repose was most marked. Thus, even small variations in the drop height in this region could lead to considerable errors.

UNE 55547:1981 standard establishes that the test material should fall freely onto a rigid steel base. However, preliminary work for the present study revealed that the 
angle of repose differs when different base materials (stainless steel, laminated steel, wood and cardboard) were used. The angle of repose was therefore determined with care for a flat, rigid metallic base (metallic base in Figure 6), and for a base made from the pellets themselves (pellet base in Figure 6). The latter was achieved using a stainless steel container with a $10 \mathrm{~mm}$ border in which the pellets first collect, thus producing a stable base of pellets over which an eventual pile forms.

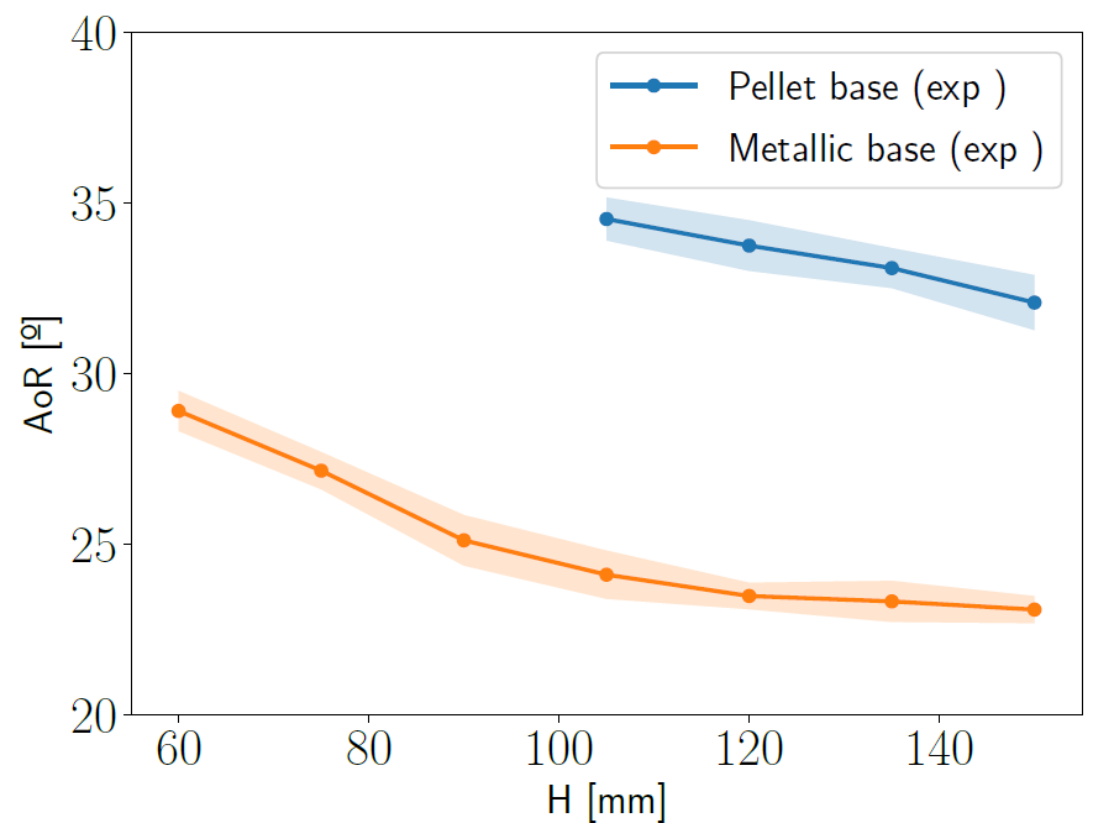

Figure 6. Variation in the angle of repose (AoR) with respect to drop height $(\mathrm{H})$ for the stainless steel base and pellet material base.

Figure 6 shows the values obtained for both bases (points represent means, shaded areas represents the standard deviation). For both, the angle of repose declined as the drop height increased. In addition, the dispersion of measurements for each drop height was small in both cases. However, the angle obtained with the pellet base was much greater than that obtained with the stainless steel base-about $10^{\circ}$ for all drop heights. Consequently, the pile of material reached the outlet of the funnel, preventing the material flowing freely. Thus, no experimental measurements could be taken for drop heights lower than $100 \mathrm{~mm}$ for the pellet base experiments.

\subsection{Numerical Simulations}

Numerous authors have reported the influence of both static and rolling coefficients of friction and their values on the angle of repose [49-51]. Figure 7 shows the means \pm SD for the angles of repose obtained in the present work for different particle-wall coefficients of friction $\left(\mu_{p-w}\right)$. All simulations considered in Figures 7 and 8 contemplated a flat, metallic (stainless steel) base plate and a drop height of $105 \mathrm{~mm}$.

The angle of repose was seen to increase with this coefficient in a non-linear fashion; the increase was greatest when the values for the coefficient were smaller. In a previous work, the authors determined the coefficient of friction for these pellets on a metallic base, but this was experimentally re-determined for the present work since the metal sample was different, and a value for $\mu_{p-w}$ of 0.2 was obtained [30]. When this value was used in the numerical simulations, the angle of repose obtained was $23.7^{\circ} \pm 0.9^{\circ}$, quite similar to the $24.1^{\circ} \pm 0.7^{\circ}$ obtained experimentally with the metallic base. 


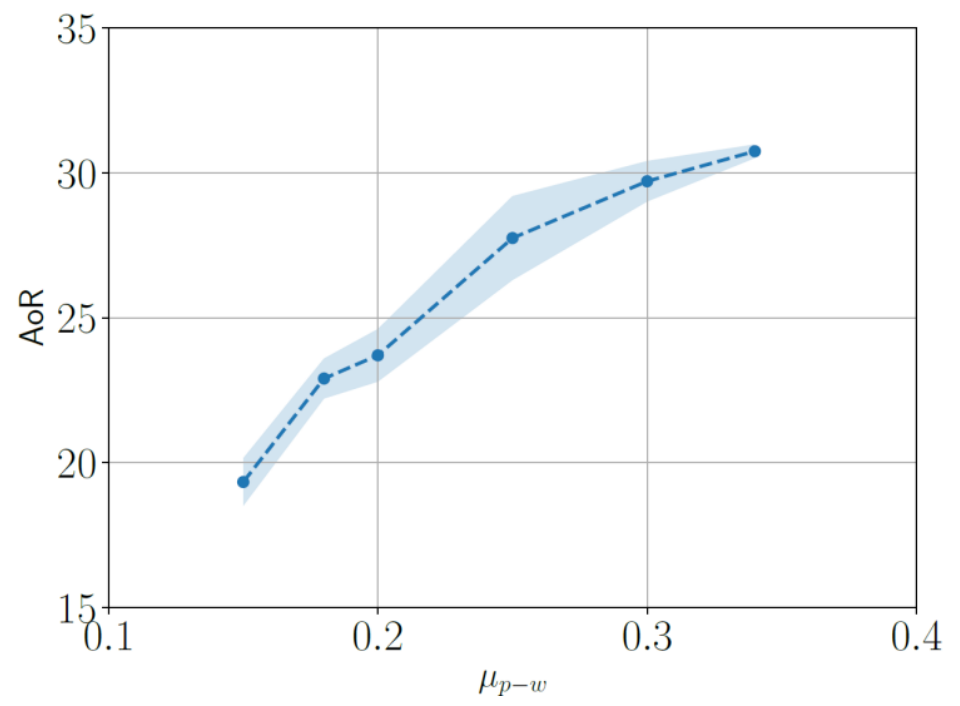

Figure 7. Variation in the angle of repose (AoR) for different particle-wall coefficients of friction $\left(\mu_{p-w}\right)$, for a metallic base and a drop height of $105 \mathrm{~mm}$.

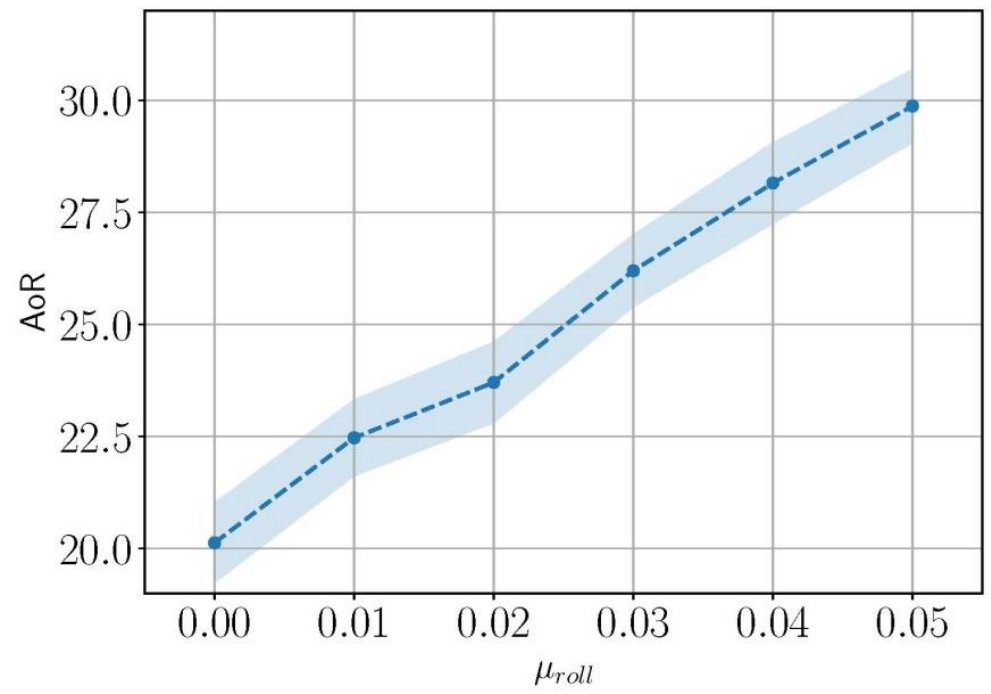

Figure 8. Variation in the angle of repose (AoR) with respect to the coefficient of rolling friction $\left(\mu_{\text {roll }}\right)$, for the metallic base and a drop height of $105 \mathrm{~mm}$.

Using the above value for $\mu_{p-w}$ of 0.2 , several simulations were next performed for the metallic base and a drop height of $105 \mathrm{~mm}$ (Figure 8) to numerically calibrate the value for the coefficient of rolling friction $\left(\mu_{\text {roll }}\right)$. Figure 8 shows the means \pm SD obtained for the angle of repose for different values of $\mu_{\text {roll }}$. The angle of repose experimentally recorded was $23.7^{\circ}$, which can be obtained for a $\mu_{\text {roll }}=0.02$ (i.e., $2 \%$ resistance to rolling). In addition, it is interesting to note the influence of $\mu_{\text {roll }}$ on the value of the angle of repose. Thus, the angle of repose changed by over $49 \%$ (from $20.1^{\circ}$ to $29.9^{\circ}$ ) as this coefficient increased from 0 to 0.05 ; the rate of increase was steady, with the relationship between these two variables largely linear over the interval examined.

Using values of $\mu_{p-w}=0.2$ and $\mu_{\text {roll }}=0.02$, numerical simulations were performed employing the obtained values for the mechanical variables. Figure 9 compares the numerical and experimental results for the angle of repose obtained for the metallic and pellet bases and different drop heights. The two sets of results coincide fully for the metallic base and differ by less than $10 \%$ (no significant difference) for the pellet base. The small differences between these sets of results thus fall within the normal range of variation for the angle of repose. Student $t$-tests with a 95\% confidence level ( $p$-value of 0.05 ) between 
both sets of results (experimental and simulation), and for all drop heights and methods were performed. It was found for all cases (drop heights and base materials) that $p$-values were larger than 0.05 , meaning that non-significant differences can be found between the experimental value and the numerical simulation value. Therefore, the coefficient of rolling friction numerically calibrated (0.02) was accurate since the numerical model can reproduce the experimental tests for different conditions. In addition, this implies the validity of the discrete element model to analyze the behavior of the pellets.

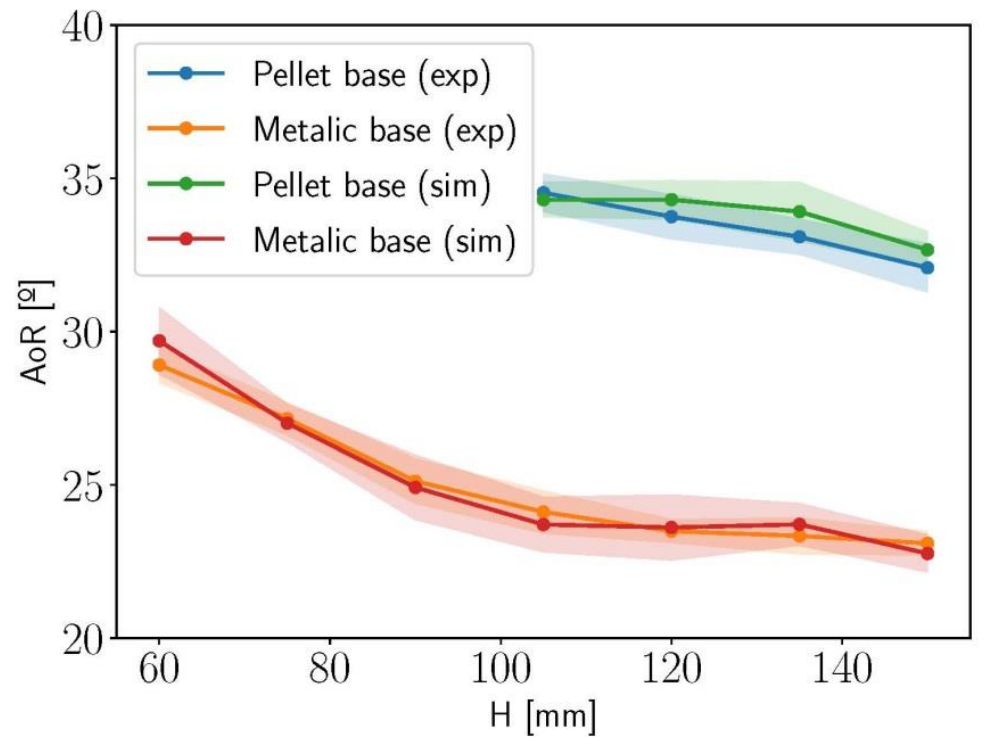

Figure 9. Variation in the angle of repose (AoR) with respect to drop height for the metallic base and pellet base: experimental and simulation results.

\section{Discussion}

The experimental results obtained (Figures 5 and 6 ) show a clear reduction in the angle of repose with increasing drop height. This is explained in that, as the drop height increases, so too does the potential energy available to a particle at the moment of its release from the funnel outlet. When such a particle hits the pile below it, the kinetic energy to be dissipated is greater, and the pellet will move further from the pile. This leads to the wider horizontal dispersion of the fallen pellets and, thus, a smaller angle of repose.

The material upon which the pellets fall had an important influence on the angle of repose. When falling onto a pellet base, the angle of repose was greater than when they fell onto a plain metallic base. This is explained by the greater coefficient of friction between the pellets than between the pellets and the metallic base, leading to a greater dispersion of energy when they fall onto a pellet base. The horizontal displacement of a falling pellet is therefore less, increasing the angle of repose. None of this is contemplated in the standards for determining the angle of repose, nor does the literature contain much information in this regard. The present work shows that such details need to be taken into account. In addition, the Spanish standard for determining the angle of repose for powdered and granular materials stipulates an interior diameter for the funnel outlet of $10 \mathrm{~mm}$, but the present work shows this is too small for assays involving biomass pellets. The outlet would become blocked. In fact, this would occur for any granular material with an effective particle diameter of over 2-3 $\mathrm{mm}$. Standards should therefore be adapted to take into account the drop height, the material forming the base onto which the particles fall and the diameter of the funnel outlet.

In the numerical simulations, the behavior of the pellets with respect to the variation in the particle-wall and particle-particle coefficients of friction was similar to that reported by other authors [49-51]. In all cases, increases in these coefficients led to an increase in the angle of repose (Figures 7 and 8), as was also observed by Zhou et al. [52] for monosized 
spheres. As explained by Zhou et al. [52], any increase in these coefficients implies a greater dispersion of energy during the discharge process. When the pellets fall onto the pile, they are therefore displaced less in a horizontal fashion, leading to a greater angle of repose and a pile with greater potential energy. In addition, an increase in the coefficient of friction is associated with a greater internal angle of friction and, thus, according to the theory of Mohr-Coulomb, an increase in the tangential resistance of the particles forming the pile. This would increase the resistance to loads in the shear direction.

\section{Conclusions}

- The procedure known as "piling" for the experimental measurement of the angle of repose needs to be adapted for use with granular materials to take into account the diameter of the funnel outlet, the material onto which the pellets fall and the height from which they drop.

- In the present work, a drop height of over $120 \mathrm{~mm}$ was required for the change in the resulting angle of repose to be insignificant. For smaller drop heights, the angle of repose increased, irrespective of all other conditions.

- The angle of repose formed for biomass pellets greatly depends on the surface roughness of the contact material on which stacking is carried out. Thus, the best way to avoid reproducibility problems when conducting simulations is to use a base of the same material that is being tested or used in real situations.

- For the present biomass pellets, an increase in the friction coefficients or the coefficient of rolling friction led to an increase in the angle of repose.

- In the numerical simulations, a coefficient of rolling friction of $\mu_{\text {roll }}=0.02$ was obtained-a tenth of the value for the coefficient of friction between the pellets. Although this value represents just $2 \%$ resistance to rolling, its influence on the angle of repose can be very significant.

- It is, therefore, vital that the coefficient of rolling friction of a material be known if models are intended to correctly predict the behavior of granular materials, the second most commonly used type of material, during their storage, transport and discharge.

Author Contributions: Conceptualization, F.A. and E.G.; methodology, J.M.F. and E.G.; software, M.A.M.; validation, J.M.F., M.A.M. and E.G.; data curation, M.A.M.; writing-original draft preparation, M.A.M. and J.M.F.; writing - review and editing, F.A. and E.G.; funding acquisition, F.A. and E.G. All authors have read and agreed to the published version of the manuscript.

Funding: This research and APC was funded by the Spanish "Agencia Estatal de Investigación" via the research project "Study of the structural behavior of corrugated wall silos using Discrete Element Models (SILODEM)", grant number PID2019-107051GB-I00/AEI/10.13039/501100011033".

Acknowledgments: The authors thank COTERRAM for providing the wood pellets used in this research. Marcos Madrid acknowledges financial support from CONICET (Consejo Nacional de Investigaciones Científicas y Técnicas de Argentina).

Conflicts of Interest: The authors declare no conflict of interest. The funders had no role in the design of the study; in the collection, analyses, or interpretation of data; in the writing of the manuscript, or in the decision to publish the results.

\section{References}

1. Duran, J. Sands, Powders, and Grains: An Introduction to the Physics of Granular Materials; Springer Science \& Business Media: New York, NY, USA, 2012.

2. Nedderman, R. Statics and Kinematics of Granular Materials; Cambridge University Press: Cambridge, UK, 1992. [CrossRef]

3. Pradhan, P.; Mahajani, S.M.; Arora, A. Production and utilization of fuel pellets from biomass: A review. Fuel Process. Technol. 2018, 181, 215-232. [CrossRef]

4. European Commission. A Sustainable Bioeconomy for Europe: Strengthening the Connection between Economy, Society and the Environment. Updated Bioeconomy Strategy; Directorate-General for Research and Innovation: Luxembourg, 2018.

5. Cheng, J. Biomass to Renewable Energy Processes; Taylor \& Francis: Boca Raton, FL, USA, 2017. 
6. Muazu, R.I.; Stegemann, J.A. Effects of operating variables on durability of fuel briquettes from rice husks and corn cobs. Fuel Process. Technol. 2015, 133, 137-145. [CrossRef]

7. Ilari, A.; Foppa-Pedretti, E.; De Francesco, C.; Duca, D. Pellet Production from Residual Biomass of Greenery Maintenance in a Small-ScaleCompany to Improve Sustainability. Resources 2021, 10, 122. [CrossRef]

8. Bioenergy Europe. Statistical Report Pellets; Bioenergy Europe: Brussels, Belgium, 2020.

9. Dyjakon, A.; Noszczyk, T. The Influence of Freezing Temperature Storage on the Mechanical Durability of Commercial Pellets from Biomass. Energies 2019, 12, 2627. [CrossRef]

10. Ståhl, M.; Granström, K.; Berghel, J.; Renström, R. Industrial processes for biomass drying and their effects on the quality properties of wood pellets. Biomass. Bioenergy 2004, 27, 621-628. [CrossRef]

11. Deng, T.; Alzahrani, A.; Bradley, M. Influences of environmental humidity on physical properties and attrition of wood pellets. Fuel Process. Technol. 2019, 185, 126-138. [CrossRef]

12. García, R.; Gil, M.V.; Rubiera, F.; Pevida, C. Pelletization of wood and alternative residual biomass blends for producing industrial quality pellets. Fuel 2019, 251, 739-753. [CrossRef]

13. Oveisi, E.; Lau, A.; Sokhansanj, S.; Lim, C.J.; Bi, X.T.; Larsson, S.H.; Mein, S. Breakage behavior of wood pellets due to free fall. Powder Technol. 2013, 235, 493-499. [CrossRef]

14. Aarseth, K.A. Attrition of feed pellets during pneumatic conveying: The influence of velocity and bend radius. Biosyst. Eng. 2004, 89, 197-213. [CrossRef]

15. Frodeson, S.; Henriksson, G.; Berghel, J. Effects of moisture content during densification of biomass pellets, focusing on polysaccharide substances. Biomass Bioenergy 2019, 122, 322-330. [CrossRef]

16. Graham, S.; Eastwick, C.; Snape, C.; Quick, W. Mechanical degradation of biomass wood pellets during long term stockpile storage. Fuel Process. Technol. 2017, 160, 143-151. [CrossRef]

17. Pa, A.; Bi, X. Modeling of Off-Gas Emissions from Wood Pellets During Marine Transportation. Ann. Occup. Hyg. 2010, 54, 833-841. [CrossRef] [PubMed]

18. Ramírez, A. The discrete element method in silo/bin research. Recent advances and future trends. Part. Sci. Technol. 2020, 38, 210-227. [CrossRef]

19. Golshan, S.; Esgandari, B.; Zarghami, R.; Blais, B.; Saleh, K. Experimental and DEM studies of velocity profiles and residence time distribution of non-spherical particles in silos. Powder Technol. 2020, 373, 510-521. [CrossRef]

20. Ayuga, F. Present and future of the numerical methods in buildings and infrastructures areas of biosystems engineering. J. Agric. Eng. 2015, 46, 1-12. [CrossRef]

21. González-Montellano, C.; Gallego, E.; Ramírez-Gómez, Á.; Ayuga, F. Three dimensional discrete element models for simulating the filling and emptying of silos: Analysis of numerical results. Comput. Chem. Eng. 2012, 40, 22-32. [CrossRef]

22. Cundal, P.; Strack, O. A discrete numerical model for granular assemblies. Geotechnique 1979, 29, 47-65. [CrossRef]

23. Gella, D.; Maza, D.; Zuriguel, I. Granular internal dynamics in a silo discharged with a conveyor belt. J. Fluid Mech. 2021, 925, A24. [CrossRef]

24. Gallego, E.; Fuentes, J.M.; Wiacek, J.; Villar, J.R.; Ayuga, F. DEM analysis of the flow and friction of spherical particles in steel silos with corrugated walls. Powder Technol. 2019, 355, 425-437. [CrossRef]

25. Madrid, M.A.; Darias, J.R.; Pugnaloni, L.A. Forced flow of granular media: Breakdown of the Beverloo scaling. EPL Europhys. Lett. 2018, 123, 14004. [CrossRef]

26. Madrid, M.A.; Pugnaloni, L.A. Velocity profiles in forced silo discharges. Granul. Matter 2019, 21, 76. [CrossRef]

27. Chen, Z.; Wassgren, C.; Veikle, E.; Ambrose, K. Determination of material and interaction properties of maize and wheat kernels for DEM simulation. Biosyst. Eng. 2020, 195, 208-226. [CrossRef]

28. González-Montellano, C.; Fuentes, J.M.; Ayuga-Téllez, E.; Ayuga, F. Determination of the mechanical properties of maize grains and olives required for use in DEM simulations. J. Food Eng. 2012, 111, 553-562. [CrossRef]

29. Wensrich, C.M.; Katterfeld, A. Rolling friction as a technique for modelling particle shape in DEM. Powder Technol. 2012, 217, 409-417. [CrossRef]

30. Agarwal, A.; Tripathi, A.; Tripathi, A.; Kumar, V.; Chakrabarty, A.; Nag, S. Rolling friction measurement of slightly non-spherical particles using direct experiments and image analysis. Granul. Matter 2021, 23, 60. [CrossRef]

31. Combarros, M.; Feise, H.J.; Zetzener, H.; Kwade, A. Segregation of particulate solids: Experiments and DEM simulations. Particuology 2014, 12, 25-32. [CrossRef]

32. Hlosta, J.; Jezerská, L.; Rozbroj, J.; Žurovec, D.; Necas, J.; Zegzulka, J. DEM Investigation of the Influence of Particulate Properties and Operating Conditions on the Mixing Process in Rotary Drums: Part 1-Determination of the DEM Parameters and Calibration Process. Processes 2020, 8, 222. [CrossRef]

33. Al-Hashemi, H.M.B.; Al-Amoudi, O.S.B. A review on the angle of repose of granular materials. Powder Technol. 2018, 330, 397-417. [CrossRef]

34. Wang, L.; Li, R.; Wu, B.; Wu, Z.; Ding, Z. Determination of the coefficient of rolling friction of an irregularly shaped maize particle group using physical experiment and simulations. Particuology 2018, 38, 185-195. [CrossRef]

35. Klanfar, M.; Korman, T.; Domitrovic, D.; Herceg, V. Testing the novel method for angle of repose measurement based on area-weighted average slope of a triangular mesh. Powder Technol. 2021, 387, 396-405. [CrossRef] 
36. Li, P.; Ucgul, M.; Lee, S.H.; Saunders, C. A new approach for the automatic measurement of the angle of repose of granular materials with maximal least square using digital image processing. Comput. Electron. Agric. 2020, 172, 105536. [CrossRef]

37. ASTM C1444-00; Standard Test Method for Measuring the Angle of Repose of Free-Flowing Mold Powders; American Society for Testing and Materials: West Conshohocken, PA, USA, 2005.

38. ISO 4324; Surface Active Agents-Powders and Granules-Measurement of the Angle of Repose; International Standard Organization: Geneva, Switzerland, 1977.

39. Gallego, E.; Fuentes, J.M.; Ruiz, Á.; Hernández-Rodrigo, G.; Aguado, P.; Ayuga, F. Determination of mechanical properties for wood pellets used in DEM simulations. Int. Agrophys. 2020, 34, 485-494. [CrossRef]

40. EN ISO 17831-1:2015; Solid Biofuels—Determination of Mechanical Durability of Pellets and Briquettes—Part 1: Pellets; European Committee for Standardization: Brussels, Belgium, 2015.

41. UNE 55547:1981; Agentes de Superficie. Polvos y Granulados. Medida del Ángulo del Talud de Vertido; Asociación Española de Normalización: Madrid, Spain, 1981.

42. Tsuji, Y.; Tanaka, T.; Ishida, T. Lagrangian numerical simulation of plug flow of cohesion-less particles in a horizontal pipe. Powder Technol. 1992, 71, 239-250. [CrossRef]

43. EDEM. Altair, User Guide; EDEM: Edinburgh, UK, 2021.

44. Li, Y.; Xu, Y.; Thornton, C. A comparison of discrete element simulations and experiments for sandpiles composed of spherical particles. Powder Technol. 2005, 160, 219-228. [CrossRef]

45. Favier, J.F.; Abbaspour-Fard, M.H.; Kremmer, M.; Raji, A. Shape representation of axi-symmetrical, non-spherical particles in discrete element simulation using multi-element model particles. Eng. Comput. 1999, 16, 467-480. [CrossRef]

46. ISO 18847; Solid Biofuels—Determination of Particle Density of Pellets and Briquettes; International Standard Organization: Geneva, Switzerland, 2005.

47. ASAE S368.4; Compression Test of Food Materials of Convex Shape; American Society of Agricultural and Biological Engineers (ASABE): St. Joseph, MO, USA, 2006.

48. Hlosta, J.; Žurovec, D.; Rozbroj, J.; Ramírez-Gómez, A.; Nečas, J.; Zegzulka, J. Experimental determination of particle-particle restitution coefficient via double pendulum method. Chem. Eng. Res. Des. 2018, 135, 222-233. [CrossRef]

49. Zhou, L.; Yu, J.; Liang, L.; Wang, Y.; Yu, Y.; Yan, D.; Sun, K.; Liang, P. DEM Parameter Calibration of Maize Seeds and the Effect of Rolling Friction. Processes 2021, 9, 914. [CrossRef]

50. Fu, J.; Chen, C.; Ferellec, J.; Yang, J. Effect of Particle Shape on Repose Angle Based on Hopper Flow Test and Discrete Element Method. Adv. Civ. Eng. 2020, 8811603. [CrossRef]

51. Li, C.; Honeyands, T.; O'Dea, D.; Moreno-Atanasio, R. The angle of repose and size segregation of iron ore granules: DEM analysis and experimental investigation. Powder Technol. 2017, 320, 257-272. [CrossRef]

52. Zhou, Y.C.; Xu, B.H.; Yu, A.B.; Zulli, P. Numerical investigation of the angle of repose of monosized spheres. Phys. Rev. E 2001, 64, 021301. [CrossRef] 